\title{
Development of E-Commerce-Based Online Web Application for COVID-19 Pandemic
}

\author{
Mohammad Monirujjaman Khan, Mahizebin Shams-E-Mofiz, Zerin Anan Sharmin \\ Department of Electrical and Computer Engineering, North South University, Dhaka, Bangladesh \\ Email: monirujjaman.khan@northsouth.edu
}

How to cite this paper: Khan, M. M., Shams-E-Mofiz, M., \& Sharmin, Z. A. (2020). Development of E-Commerce-Based Online Web Application for COVID-19 Pandemic. iBusiness, 12, 113-126. https://doi.org/10.4236/ib.2020.124008

Received: October 5, 2020

Accepted: November 23, 2020

Published: November 26, 2020

Copyright (c) 2020 by author(s) and Scientific Research Publishing Inc. This work is licensed under the Creative Commons Attribution International License (CC BY 4.0).

http://creativecommons.org/licenses/by/4.0/

(c) (i) Open Access

\begin{abstract}
A grocery shop is a retailing shop where a general range freshly packed food products are available. On an everyday life people have to use a grocery shop to get their livelihood items. To buy the necessary products people visit a grocery shop, collect the products from different shelves and then pay for the item and proceed. But many times this process does not seem very convenient. People nowadays are very busy. In their busy schedule they always forget to make time for grocery shopping. Some people try to avoid it because of traffic jam, just to avoid gathering of people. Moreover, in this global COVID-19 pandemic it can turn into a life threat for a person or family as well as a nation. Considering all the issues and reasons behind the issues we think online grocery store can be the best solution to all the problems. This paper presents the development of web-based online grocery store where people can do shopping using a computer or a smart phone sitting at their home very easily. Though online shopping has been known as a rapidly growing business, and although online grocery shopping has not followed these same growth patterns in the past, it is now being recognized for its potential. There will be an admin panel and a user panel. Users have to use a Gmail to log in and create an account to do shopping. Admin always use their Gmail to maintain the product availability, the website, the customers and more. This system is user friendly and it can make people life very easy, safe and time-saving specially in the e-commerce demanding period of this COVID-19 crisis.
\end{abstract}

\section{Keywords}

Internet, Web Application, E-Commerce, Food, COVID-19, Pandemic, Users, Admin, Grocery, Online, Coronavirus

\section{Introduction}

The novel coronavirus disease (COVID-19) has impacted the daily life of many 
people. In an attempt to limit the spread of COVID-19, individuals have changed how and how much they produce and consume. According to data on household consumption in the world, expenses grocery delivery and other categories changed substantially from week to week during the early stage of the COVID-19 pandemic. Next to the health care industry, the food industry is arguably the most affected by the pandemic. In the Bangladesh most eating establishments have been mandated by the government to close temporarily. However, even during the pandemic, groceries are still basic human necessities. More recent studies have explored the role of online grocery shopping attributes on purchasing behavior, including delivery costs, delivery times, and minimum order thresholds. Are there significant differences in consumer preferences for grocery shopping attributes when the number of new COVID-19 cases is increasing, constant, or decreasing? The trend in the number of new COVID-19 cases may affect consumer behavior, as there is risk of contamination in case of physical proximity with other people. Consumers may use information on the number of new COVID-19 cases to help make decisions (Melton, 2020).

This study will focus more specifically on online grocery shopping. The retail grocery industry has during the immediate phases of COVID-19 witnessed changes in collective patterns of consumer behavior, even a radical change in demand for certain products, online shopping and home delivery services. To a degree these changes result from restrictions and recommendations from national governments and different local and global authorities to protect especially persons belonging to a COVID-19 risk group, but also from drivers in the minds of the consumers to protect themselves, the ones close to them and people they meet, or are in contact with. Retailers of essential products such as grocery item have, due to increased demand and requirements, faced challenges of inventory, logistics management and keeping their stores a safe environment. In crises retail consumers change their preferences regarding such things as what goods to buy. Consumers are also likely to learn or develop new grocery shopping routines due to a crisis like COVID-19. Understanding consumer buying patterns emerging in crises plays an important role in the success of online grocery shop (World Health Organization, 2020).

Shopping for food and grocery products has witnessed a revolution in every retail market with the conspicuous changes in the consumer buying behavior driven by strong income growth, changing lifestyles and cost effective and efficient online and mobile technologies. As consumers allocate less time to shopping and more to other endeavors, their desire for convenience has mounted and their attention has been frequently diverted to virtual shopping as an alternative medium. Thus the rapid evolution of internet is changing the way customers shop and buy products and services and has rapidly evolved into a global phenomenon. So the shopping convenience has been one of the principal motivations underlying customer inclinations to adopt online purchasing. Online grocery, although still quite small, is gaining traction and becoming increasingly integrated into the daily life of Bangladesh consumers in every area. Despite the 
growth and importance of online grocery, little is known about how people shop online for groceries. Previous studies identified factors influencing on-line buying behavior; challenges faced by on-line retailers but could not identify the purchase behavior of Bangladesh grocery consumers (Kaur \& Shukla, 2016). Moreover, some studies have been conducted to investigate the determinants of customer intentions for online grocery shopping. Till now, there is no consensus on what are the factors that actually influencing people to shop grocery items through Internet. However, researchers have suggested that as compared to traditional consumer behavior, online behaviors of consumers are subtlety different in nature because of unique characteristics and interplay of technology, culture and differences in diffusion of e-commerce (Grashuis, Skevas, \& Segovia, 2020).

\section{Proposed System}

\subsection{Introduction}

We developed an "Online Grocery Shop" web application for all the people that can make shopping easy, safe, fun, effective and can save the time as well. Figure 1 shows flow chart diagram of online e-commerce shopping web app. It includes the features that are mentioned in the flowchart. The system consists of two user profiles as shown in Figure 1. There is a customer account and an admin account. Customers can order products through the account by a valid Gmail and a secure password. They can confirm their order after successful registration process. Customers can make many changes along with the order in this section. In the admin account now we have a registered admin which is my group mate. She/he is a fixed admin here. If we handover the website to a company and there occurs a necessity of adding another admin or change the admin then it need to be done through the database directly. So all the changes can be happened after a successful registration and login in the database admin panel.

All the features are divided into two consecutive panels: the Admin and the Customer or User.

\section{Login Panel for Both User \& Admin:}

The system consists of two user profiles as shown in Figure 2 and Figure 3. There is a customer account and an admin account. Figure 2 provides the registration and login page of the users. Customers can order products through the account by a valid Gmail and a secure password. They can confirm their order after successful registration process. Customers can make many changes along with the order in this section.

In the admin account now we have a registered admin which is my group mate. She/he is a fixed admin here. Figure 3 shows admin login portal of the system.

If we handover the website to a company and there occurs a necessity of adding another admin or change the admin then it need to be done through the database directly. So, all the changes can be happened after a successful registration and login in the database admin panel. 


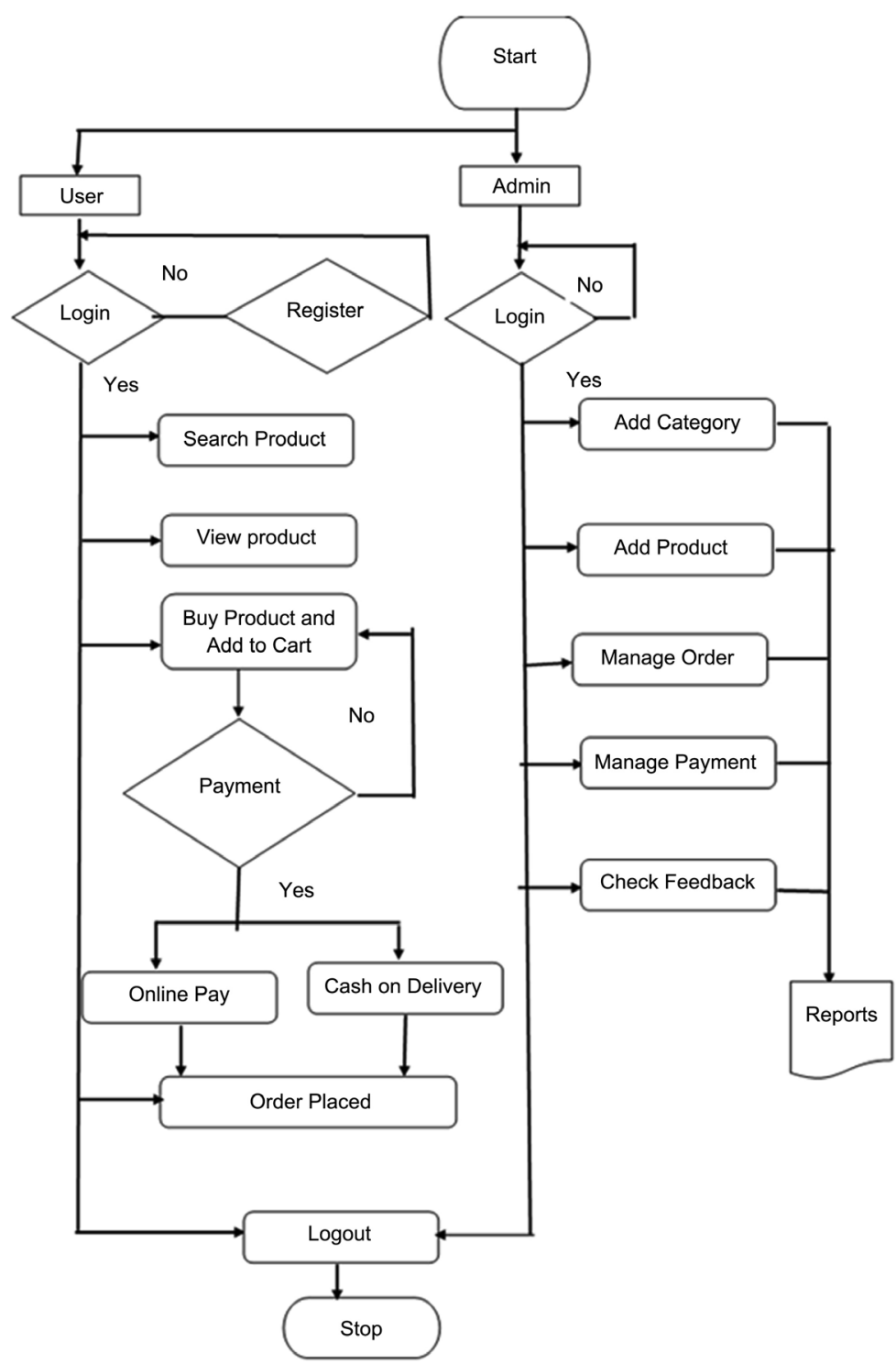

Figure 1. Flow chart diagram (Online e-commerce shopping web app).

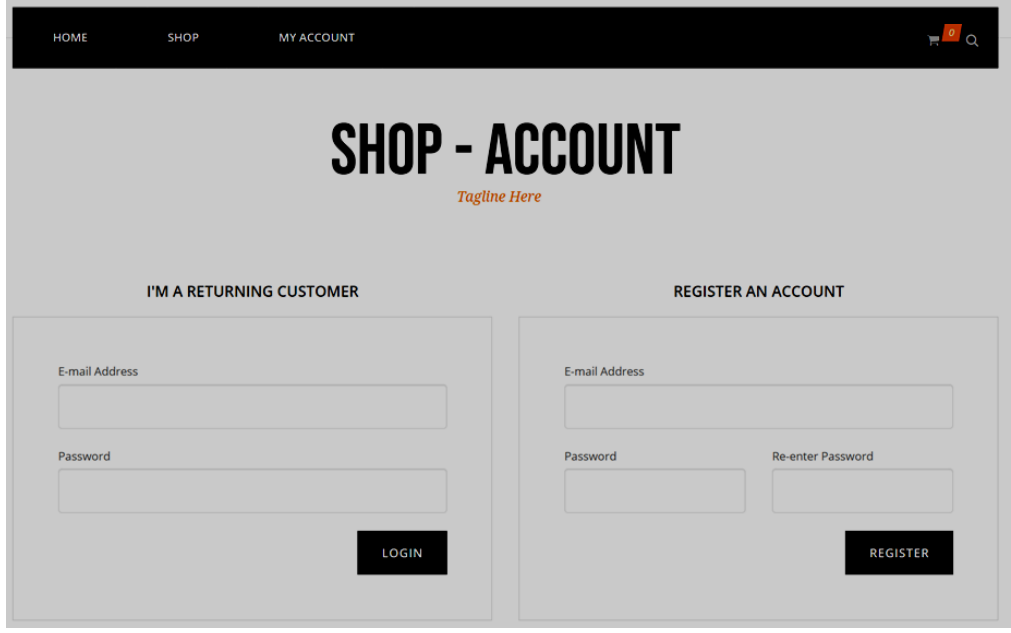

Figure 2. Log in and registration page for user. 


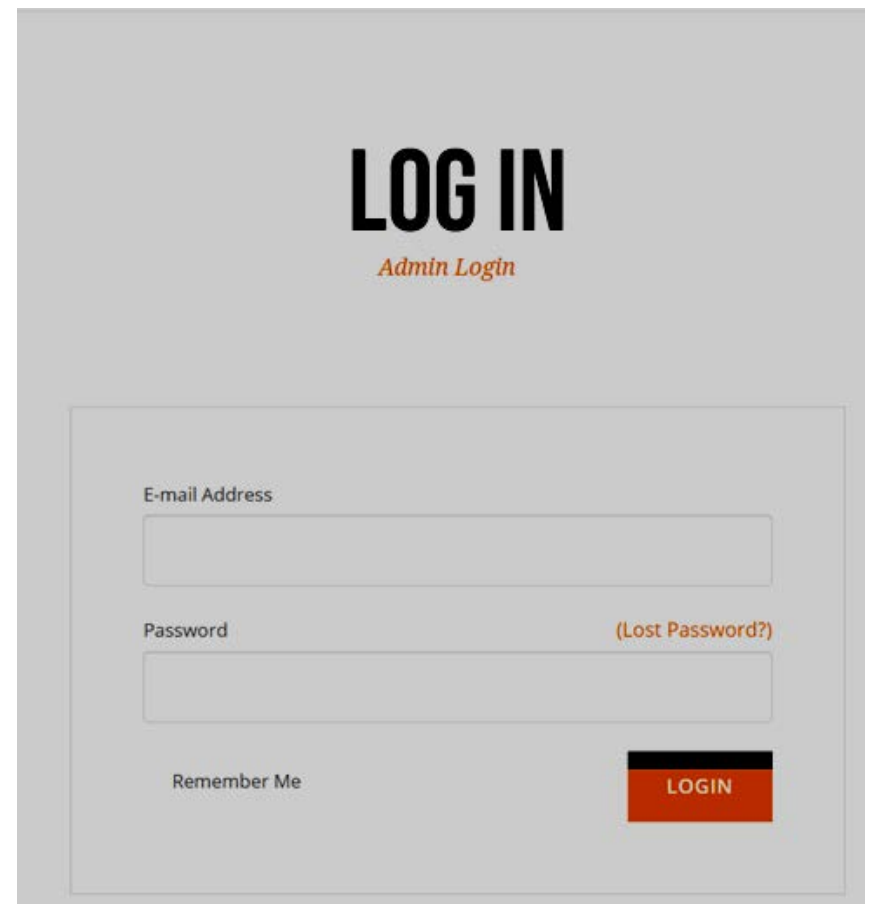

Figure 3. Admin login portal.

\subsection{User Panel}

In the user panel when a consumer searches for our website he or she will get more pages. When he or she clicks on the first page user will be able to see a home page first. Figure 4 shows the home page of the developed e-commerce web application. In the home page all the available products and categories can be seen all together. We can have a look. This is the main landing page of the web application.

1) Shop

In admin panel we add something in category option. The shop section of user panel is auto updated.

\section{2) My Account}

In this option there are my orders, update address and log out function. In my orders section there are login and register two functions. If anyone orders something in our website they must be login first with their mail id and if they are new customer they must be register with mail ID. After log in the account page takes the customer to the checkout page to fill all the necessary data to confirm his order. When he puts all the data he is all set to receive his order. Now we can see the form icon the next page.

Figure 5 shows the shortcut way to change address in the user panel. Consumers have to fill all the gaps. Unable to fill any gap or forget to fill any of them can make the order process delay. They have to click on the I've agreed option as well to complete the order, users also can update their information by update account. By filling the form again their address will be updated in the database. The admin can see the updated address of the consumer. 


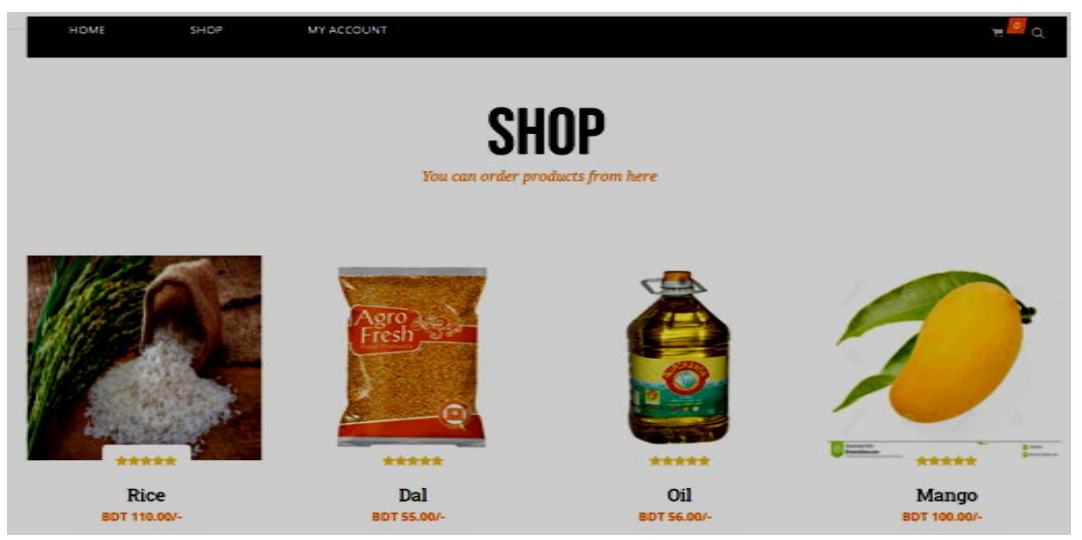

Figure 4. User home page.

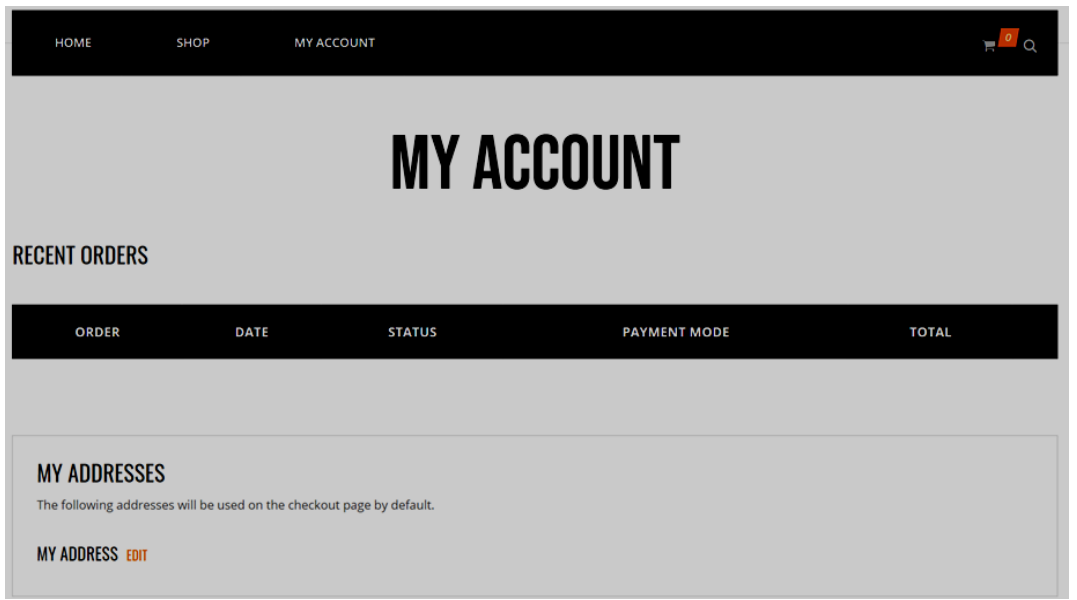

Figure 5. Shortcut way to change address in user panel.

Another shortcut to see the product list is to check the cart on the right side of the home page. Now if any customer wants to know the details of any product then he has to click on the product and after that he can know the description. When he clicks on the left he can see the details. Along with the details he can know the reviews and can also add the product in his Wish list for further shopping. But if he clicks on the right he can directly add the product to the cart in short. After all the quarries and shopping he can log out from the page by clicking My Account > Log Out.

\subsection{Admin Panel}

Admin panel contain many features like dashboard, categories, product, order etc. An Admin has all the power and control to deliver a product, cancel a product, discontinue a product, increase and decrease the price of product and product list.

All the pages also have sub options to make the page user friendly.

\section{1) Admin Dashboard}

It's where we create and manage content, add functionality in the form of plug-in, change styling in the form of themes. The "dashboard" is often dis- 
played on a web page which is linked to a database that allows the report to be constantly updated. Figure 6 shows the admin home page.

In view Categories admin can see the existing categories of product. After that if he wants to edit the category then he can do that by doing some changes or if he wants to delete the category he can do that in the page. As well as for this command on other way he will have to do that in the database.

\section{2) Categories}

In categories option there are two sections, view category and add category. If we want to add some categories in add category section then it will be shown in view categories. And there are also edit and delete option. If we delete or edit something that also be shown in view categories.

\section{3) Product}

Product option is same as categories option. Like there are also two sections for product view and add product and it's also act same as categories function. View products also have the same rules and also can be generated through database.

\section{4) Orders}

In this function there are all of order that admin is received from users. And there is also shown the order details here. View orders also have the same database and list page to follow the order track. Figure 7 illustrates the order lists of the customers with details in data base.

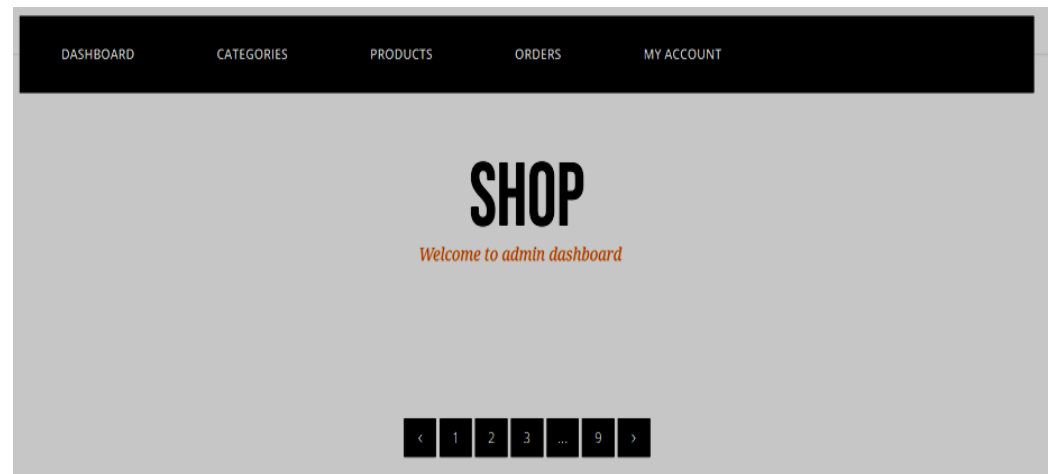

Figure 6. Admin home page.

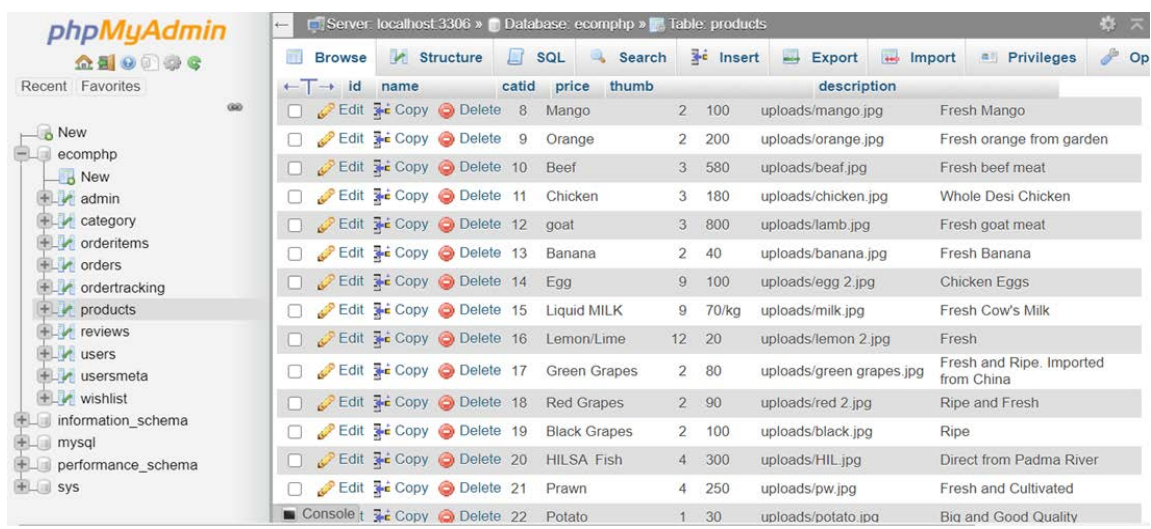

Figure 7. Order list of customers with details in database. 
With this option admin can manage the orders very easily. Admin can delete and postpone the order for any kind of unavoidable circumstances. Add Product and Category follow the same formula. Admin will fill a form to add.

\section{Design Impact}

In this chapter, we discuss about the various impacts that our website has been able to generate.

\subsection{Current Pandemic (COVID-19) Impact}

The coronavirus COVID-19 has affected more than 211 countries and territories globally. Figure 8 shows the current statistics of COVID-19 (number of cases and deaths) for both male and female. Governments across the world are taking stringent precautionary measures and issuing advisories to ensure people do not come out of their houses and the chain of coronavirus is broken. The majority of people are following the guidelines given by their respective government officials. However, shopping of groceries may be single important task other than the healthcare, which has been forcing people to leave their house and enhance the risk of possible contact with the infected.

The COVID-19 pandemics situation has changed the consumer's way of shopping grocery. Consumers are increasingly taking online grocery platforms to buy even the perishables such as milk, eggs, and bread. Many online grocery providers are assisting local administrations to manage doorstep and contactless deliveries for safety measures. However, the online grocery market is facing challenges due to the pandemic. There is an increasing pressure on supply chain for delivering the products. The another challenge is, employees, as the online grocery providers need to equip their employees with proper resources and trainings to manage operations remotely with little or no disruption (Market Research Future, 2020). Due to corona problem there was quarantine people could not go out the price of the products increases and the effects of that are
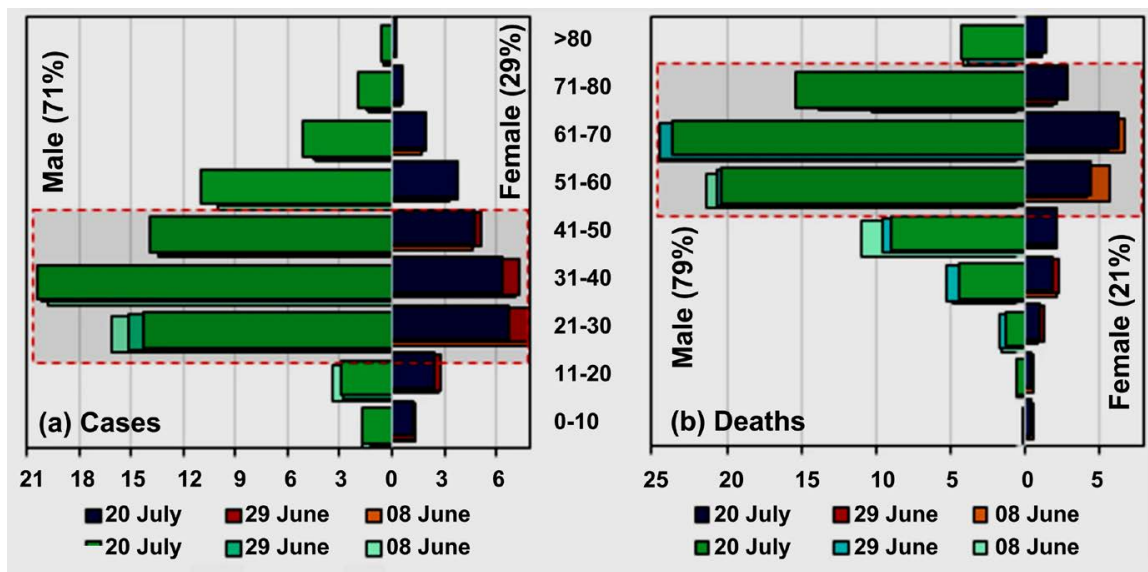

Age-sex composition of COVID-19 (as of 20 July 2020): a reported cases and $b$ deaths. $X$-axis represents $\%$ of the total number of cases/deaths and $y$-axis represents age group. Shaded portion represents most vulnerable groups

Figure 8. Current statistics of COVID-19 (no of cases/deaths). 
still remains. The price of the products is increasing and due to the effect of importing the products from another country. Nowadays it takes more money $t$ import the products and seller takes more money from the customers. This is a huge changed of the market due to corona virus pandemic. Figure 8 shows current statistics of COVID-19 (no of cases/deaths). It means still the number of COVID-19 patients are huge and second wave has already increased in Europe and USA therefore the demand of online e-commerce will be increased and in order to meet this demand new startup in the sector of e-commerce can play an important role to meet the demand of current market.

\subsection{Environmental Impact}

Online shopping can be greener than driving to the store. Novel last-mile alternatives to conventional delivery trucks stand to make it even more environmentally friendly. The purchase that doesn't happen has the lowest delivery carbon footprint of all (Pearce, 2019). Since online shop deals with digital shopping system therefore less bad impact will be on the environment.

\subsection{Economic Impact}

Online purchases take money out of the local economy. Less money comes to local businesses, which means they make fewer hires. Fewer hires mean less money flowing into the local economy. Less money flowing into the local economy means fewer jobs, and less money available to residents to spend (Aguirre, 2020).

Consider these online shopping statistics: 69 percent of people have bought something online. Between 4 and 10 percent of retail sales happen online. A quarter of adults in the country buy something online at least once a month. During the 2018 holiday season, $\$ 126$ billion was spent on online purchases in this country (Aguirre, 2020).

All of these purchases are purchases that are not being made in a brick and mortar store. And that means that all of these purchases are having a measurable impact on the local economy. Is this impact bad news for local business? The reality is a little more complex.

\subsection{Social Impact}

Due to online shopping is becoming more and more popular, there will have a lot of issues like, privacy, cheating, Fraud and security concerns, consumer expectation and etc. Online shopping websites is built to allow people to sell and advertise their item or buy any things that they needed via website (UKEssays, 2018). Through creating new online e-commerce business will open the door for the job seekers, many unemployed people will get job. Job market will be created for the poor people. Busy people can save their time through online shopping. They can spend their time for other important work. In our country there are huge traffic Jam which causes huge waste of time of people so online marketing 
will save lot of time of people.

\subsection{Sustainability}

When we go through the history ordering groceries online became popular in the 1990s, in the United States, during what has been called the dot-com boom (Saunders, 2018). When popularity was short-lived, however, and several online shopping services faced bankrupt. Online grocery delivery services are available throughout Europe, Asia and North America, mostly in urban centuries. Over the next few years, some of them survived economic hardship to remain strong in the market, and today there are numerous online grocery retailers.

COVID-19 has significant impact on e-commerce of the world and in some cases negative impact but overall e-commerce is growing rapidly because of virus. It has changed the nature of business. According to research 52\% consumers avoiding to go brick and mortar shopping and crowded areas. Furthermore, 36\% avoide brick and mortar shopping until they get corona-virus vaccine. Coronavirus effects different on different nature of products, means the impact of COVID-19 on several products is very high and on some product less impact. Overall sale of e-commerce increases because of this virus, people avoiding to go out, keeping social distance and buying from home, working from home such as Wal-Mart grocery e-commerce increases $74 \%$. Moreover, the media usage also increased in this time and Face book, Google update their features to connect more people in single time such as Face book introduce messenger for 44 people that is competing to Zoom (Bhatti et al., 2020). Similarly, Google also launched updated version. Coronavirus compelled to customers to use internet and make it habit in their daily routine. Furthermore, many challenges facing by retailers in e-commerce, such as extend the delivery time, difficulty face during movement control, social distance and lockdown. The process of shipment and supply is quite slow now, but still people buying because they do not have another alternative. Hence, people moving towards technology due to virus. Furthermore, some products are very high in demand in market. Even retailers cannot fulfill the customer's demands such as hand sanitizers, disposable gloves, grocery, and daily products. Figure 9 shows the e-commerce market size in Bangladesh. On the other hand, negative effect of COVID-19 on tourism industry, flights are in loss, international trading is very slow and stuck in their position.

Our system has been able to deal with huge number of users at a time. Now in this global pandemic this is the only way to survive. Therefore based upon these facts and continuous testing, our system is sustainable. The online grocery shopping behavior might continue even after the period of social distancing ends, influencing consumers while selecting a retail channel. In our country there are existing e-commerce like Chaldal, Monisho Ltd. their revenue has been increased a great number and another one Shopup received huge fund in this field and they are growing very fast. In addition huge number of women is also becoming entrepreneur nowadays. The market of e-commerce based on current situation is 


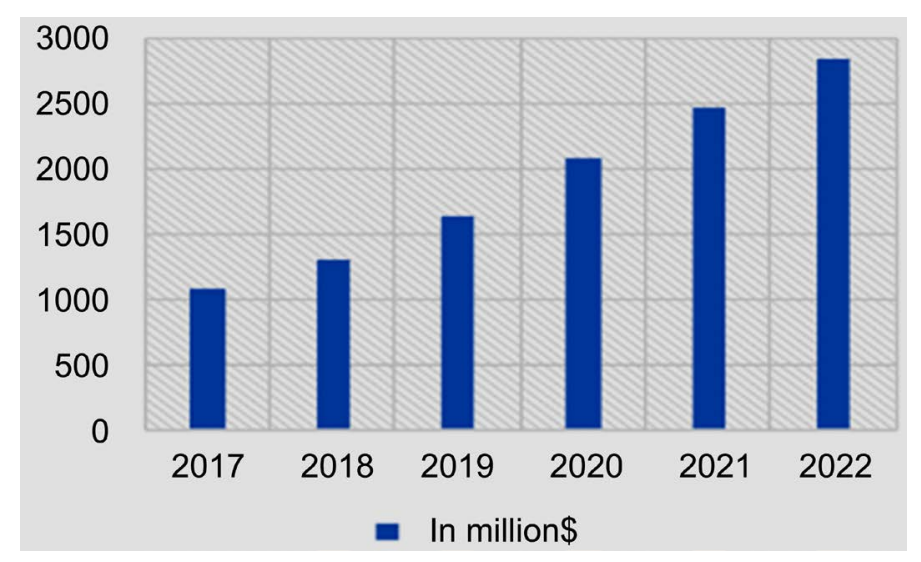

Figure 9. Bangladesh e-commerce market size.

huge and it will be increasing due to the facilities of internet and smart mobile phone that most of the people have even in the village area.

\subsection{Summary}

This chapter has covered the different types of impacts that our website offers and those has been described and discussed. From the above given impacts we can conclude that our designed website is good enough to use under any circumstance.

\section{Conclusion}

Over population is the major problem in Bangladesh. For this huge population people waste their valuable time on road in traffic jam. Technology has made significant progress over the years to provide consumers a better online shopping experience and will continue to do so for years to come. With the rapid growth of products and brands, people have speculated that online shopping will overtake in-store shopping. Online based stores can minimize the number of people in different types of places as well as on roads. Online grocery services meet a number of consumer needs including providing products for markets or helping the time starved consumer shop for the mundane weekly groceries. By delivering products to consumers' homes, the homebound aged and handicapped can participate in the shopping experience. Even though there has been a great decline in the number of pure-play online stores, there appears to be a solid market for shopping online. Using modern technologies we approach to build this website that can make people life easy. This model is effective as it creates distribution efficiencies and leverages reputation, which is an important consideration for consumers in light of the perishable nature of many grocery products. Even though the website has few features it can be used by any kind of grocery companies easily. Because it contains all the main features that a grocery shop need. This system can help people make life easy, time-saving, and comfortable and also can put a remark on the economy of Bangladesh. In exchange, online shopping has opened up doors to many small retailers also that would 
never be in business if they had to incur the high cost of owning a brick and mortar store. In the end, it has been a win-win situation for both consumer and sellers.

\section{Future Work}

The main objective of developing this system is to provide a basic platform for startup an online grocery shop. The system can be more improved than the current form. As our system is a web-based, various forms of new features can be incorporated to this system as per the requirements. In the context of securing this system further work can be done by including firewalls and other means of securing this system. Additionally, the interface of the system can be a work in progress to look more user-friendly.

There are some features that can be added such as:

\subsection{Can Have an Android Version}

First we work on converting the website into an android or iOS mobile application. This will help the website to grow more rapidly among people.

\subsection{Signup with Social Media and Mobile Number}

Today, customers do not like to fill the long sign-up forms while registration. Giving instant access to customers through social media profiles have been a great way to retain more customers and increase the number of visits to your online grocery mobile app. Furthermore, there are some customers who hesitate to sign up with social media due to security or privacy reasons, for such customers giving them an option of one-click signup form with email or mobile number is a better idea. The sign up section can be updated by including the popular social media sites. When a user wants to sign up for an account it can be made easier by incorporating the mainstream social media sites such as signing with one's Face book or Twitter profile.

\subsection{Product Return}

It is the most important concern of the customer whether the product will be replaced or not in case of any damage or other related problems. So it is a must add feature that will allow the customer to return the products.

\subsection{Coupon Codes and Special Deals, Referrals and Rewards}

Who won't like the special attention, similarly if the website admin are giving coupon codes to its customers on their every purchase, it will make them happy and encourage them to purchase more. According to stats shared by investigation team, 31 million coupons will be redeemed worldwide in 2019 and 62 per cent smartphone users are likely to use digital coupons in the future. Additionally, giving special deals on festivals or running contents are proved strategies to increase sales on your online grocery website. This feature will create interest for 
the customers (as they can earn rewards by referring) and they will refer your products to their friends. It will help your business to grow (Mahajan, 2018).

\subsection{Summary}

This chapter has described the possible future applications of the design. But there are a lot of possibilities with the designed system. The system may need some research for different applications, though the principle of the designed system will remain as it is. The limitation can be initially we will need manpower to run the startup therefore fund can be a big issues and getting also the skilled people to run the business. A very good team is a main strength for a startup to improve further.

\section{Acknowledgements}

Authors of this paper would like to thank to the Department of Electrical and Computer Engineering, North South University, Dhaka.

\section{Conflicts of Interest}

The authors declare no conflicts of interest regarding the publication of this paper.

\section{References}

Aguirre, V. (2020). How Online Sales Impact the Local Economy: The Good and the Bad. https://blog.becomedistinct.com/blog/how-online-sales-impact-the-local-economy-the -good-and-the-bad

Bhatti, A., Akram, H., Basit, H. M., Khan, A. U., \& Naqvi, S. M. R. (2020). E-Commerce Trends during COVID-19 Pandemic. International Journal of Future Generation Communication and Networking, 13, 1449-1452.

Grashuis, J., Skevas, T., \& Segovia, M. S. (2020). Grocery Shopping Preferences during the COVID-19 Pandemic. Sustainability, 12, 5369. https://doi.org/10.3390/su12135369

Kaur, H., \& Shukla, R. K. (2016). Consumer's Attitude towards Online Grocery Shopping in Delhi City. International Journal of Multidisciplinary Approach and Studies, 3, 29-40.

Mahajan, A. (2018). Must-Have Features of an Online Grocery Shopping Mobile App. 24 September 2018.

https://www.itproportal.com/features/must-have-features-of-an-online-grocery-shoppi ng-mobile-app/

Market Research Future (2020). Impact of COVID-19 Outbreak on Online Grocery Market-Forecast Till 2022. April 2020.

https://www.marketresearchfuture.com/covid-19-analysis/covid-19-impact-online-gro cery-market-9546

Melton, J. (2020). Online Grocery Shopping Soars during the Corona Virus Crisis. https://www.digitalcommerce360.com/2020/03/30/online-grocery-shopping-soars-duri ng-the-coronavirus-crisis/

Pearce, F. (2019). Is Cyber-Shopping Terrible for the Environment?23 May 2019. https://ensia.com/features/environmental-cost-online-shopping-delivery/

Saunders, N. (2018). History behind Online Grocery Shop. 
https://www.onespace.com/blog/2018/10/online-grocery-lessons-history/

UKEssays (2018). The Impact of Online Shopping on Society Information Technology Essay. November 2018.

https://www.ukessays.com/essays/information-technology/the-impact-of-online-shopp ing-on-society-information-technology-essay.php?vref $=1$

World Health Organization (2020). Q\&As: Food Safety and Nutrition Related to COVID-19. 14 August 2020.

https://www.who.int/emergencies/diseases/novel-coronavirus-2019/question-and-answ ers-hub/q-a-detail/food-safety-and-nutrition\#: :text=delivery 